\title{
An Analysis of Internet Catchwords from the Perspective of Conceptual Blending Theory
}

\author{
Meng Li \\ School of Foreign Languages, Beijing Forestry University, Haidian District, Beijing 100083, China \\ Email: limengbiye@163.com \\ Yueqin Gao \\ School of Foreign Languages, Beijing Forestry University, Haidian District, Beijing 100083, China \\ Email: yueqingao@yahoo.com
}

\begin{abstract}
Internet catchwords are the popular on-line phrases or utterances coined by net citizens during their long-time internet practice. These phrases or utterances are innovative, humorous and widely spread, which fully show the personalities and life styles of the users. Developed from the mental space theory, conceptual blending theory is an important part of cognitive linguistic researches. Based on this theory and integration networks, this paper will explain the meaning construction of internet catchwords and the way people understand them. It proves that conceptual blending theory can provide detailed description and profound explanation of the perceiving process of internet catchwords. Meanwhile this paper will testify the cognitive explanation power of the conceptual blending theory.
\end{abstract}

Index Terms -internet catchwords, cognitive explanation, conceptual blending theory, integration networks

\section{INTRODUCTION}

Internet catchwords are popular on-line phrases or utterances. They are innovative, humorous and widely spread, which fully show the personalities and life styles of the users. Through the research of the internet catchwords, people can witness the changes of social culture and social value.

Conceptual blending is argued to be a fundamental cognitive operation that is central to general properties of human thought and imagination (Evans \& Green, 2006). Since conceptual blending is a new round cognitive operation based on the normal conception structure, it has always been used to explain certain linguistic phenomenon. As for the internet catchwords, even though people do not realize it, how we understand them is nothing else than the explanation given by conceptual blending theory which integrates the distinctive input spaces.

Certifying the role that conceptual blending theory has played in perceiving internet catchwords by analyzing examples is the research method and highlight of this paper. Through this, readers will have a better idea about how these internet phrases and utterances can be endowed with new meanings from the perspective of cognitive linguistics.

\section{LITERATURE REVIEW}

\section{A. The Formation and Development of Conceptual Blending Theory}

The origins of conceptual blending theory lie in the research programs of Gilles Fauconnier and Mark Turner. While Fauconnier had developed Mental Spaces Theory in order to account for a number of traditional problems in meaning construction, Turner approached meaning construction from the perspective of his studies of metaphor in literary language. Fauconnier and Turner's researches converged on a range of linguistic phenomena that appeared to share striking similarities and that resisted straightforward explanation by either of the frameworks they had developed. Fauconnier and Turner both observed that in many cases meaning construction appears to derive from the structure apparently unavailable in the linguistic or conceptual structure, functioning as the input to the meaning construction process. Conceptual blending theory emerged from their attempts to account for this observation (Evans \& Green, 2006).

Conceptual blending theory is based on the mental space theory. "Mental spaces are small conceptual packets constructed as we think and talk, for purposes of local understanding and action.... [They] operate in working memory but are built up partly by activating structures available from long-term memory." (Ungerer \& Schimid, 2001, p.258). Since Fauconnier and Turner first advanced their theory in a seminal paper in 1994, a considerable amount of evidence for conceptual blending has been amassed from a range of non-linguistic phenomena (Evans \& Green, 2006).

Based on the mental space theory, Fauconnier and Turner (1995) formally put forward the cognitive operation model of human's mental space---conceptual blending---in the paper "Conceptual Integration and Formal Expression". In the book "Mappings in Thought and Language" (Fauconnier, 1997), Gilles Fauconnier points out the "four spaces" model, namely generic space, input space 1 , input space 2 and blending space. Meanwhile, he emphasizes that it is the cross 
domain mapping, space chain, structure project, conceptual blending and other unconscious action that create dynamic meaning of natural language. "Conceptual Integration Networks" (Fauconnier \& Turner, 1998a) holds the idea that Conceptual integration- "blending"-is a general cognitive operation on a par with analogy, recursion, mental modeling, conceptual categorization, and framing. In blending, structure from input mental spaces is projected to a separate, "blended" mental space. The projection is selective. Through completion and elaboration, the blend develops structure not provided by the inputs. Inferences, arguments, and ideas developed in the blend can have effect in cognition, leading us to modify the initial inputs and to change our view of the corresponding situations. In 1998, "Principles of Conceptual Integration" by Gilles Fauconnier and Mark Turner was published. It discusses the rules in the complex cognitive operation so as to optimize the conceptual blending theory. Fauconnier (1999) points out how blending theory reflects the presumptions and methodology. Fauconnier and Turner (2000) believe that compression enables people handle long logic chain. They examine how blending achieves compressions over vital relations, and thereby achieves one of its important sub goals: the provision of global insight. Grady (2000) illustrates composition, completion and elaboration during the process of selective projects and blending.

"The Way We Think" by Gilles Fauconnier and Mark Turner which is published in 2002 can be treated as a milestone in the development of conceptual blending theory. It upgrades conceptual integration to be the basic psychological cognitive mechanism for nearly all cognitive activities. Fauconnier and Turner argue that our ability to perform conceptual integration or blending may have been the key mechanism in facilitating the development of advanced human behaviors that rely on complex symbolic abilities. They emphasize that it is compression that enables the blending from input space to the blending space. The vital relationships in compression are mainly time, space, value, analogy and cause and effect. Furthermore, based on the research of 1998, Fauconnier and Turner (2002) put forward the types of conceptual blending networks, namely simplex networks, mirror networks, single-scope networks and double-scope networks. Meanwhile, conceptual blending can get rid of the restriction of the single network, since there can be more than one input space and the blending space of one network can also be the input space of another network. In addition, they make an explicit statement on those operational principles and working rules, which are topology principle, principle of integration (gestalt principle), principle of unpacking, principle of relevance and principle of human scale.

Fauconnier and Turner (1999, 2000), Grady (2005), and Grady et al (1999), comparing and contrasting conceptual metaphor theory with conceptual blending theory, conclude that the two approaches treat related but complementary phenomena. Conceptual blending combines the speech and action structure and dynamic features of metonymy and metaphor. While metonymy and metaphor project from source domain to the target domain which comes from the original structure in the source domain, the process of conceptual blending is dynamic, in which a new blending space and emergent structure will be established.

\section{B. The Researches of Conceptual Blending Theory in China}

The researches of conceptual blending theory in China mainly explore the theoretical development of conceptual blending theory and its applications, which cover the fields of theoretical development and front issue of conceptual blending theory, the comparative study of conceptual blending theory and conceptual metaphor theory and the application of this theory in the explanation of advertising, literature, jargon, Internet language, translation, English word formation, syntax, and discourse structure analysis. It has proved that conceptual blending theory can provide detailed description and interpretation of the psychological mechanisms in understanding cultural and linguistic phenomenon. Its explanation power has been validated in many areas, verifying its vitality and practical value. Conceptual blending theory has been experiencing various improvement and certification since it was first proposed by Fauconnier in 1994. Up to now, conceptual blending theory has been applied to broader areas, meanwhile cross- and interdisciplinary researches continue to emerge. Through conceptual blending theory, one can understand the cognitive processes of language phenomenon and words formation from the microeconomic perspective. The diversified development of Conceptual Blending theory is in accordance with the develop trend of linguistics today.

The theoretical researches of conceptual blending theory in China can be mainly divided into two aspects: the sole research and the comparative research. Concerning the sole research of conceptual blending theory, Wang (2006) and Zhang \& Yang (2008) review the development of this theory based on its foreign researches. Meng (2004) and Wei (2010) point out the advantages and deficiencies of conceptual blending theory. As for the comparative researches between conceptual blending theory and other linguistic theory, Lu (2010) examines the common theoretical premises and similar on-line reasoning of conceptual blending theory and relevance theory. Huo (2010) explores the differences and complementation of conceptual blending theory and prototype theory from the perspective of explanation of euphemism.

The researches of the application of conceptual blending theory in the explanation of linguistic and cultural phenomenon in China are fruitful: Wang (2007) and Zhou \& Bai (2006) discuss how to understand the English word formation process from the perspective of conceptual blending theory. Huang (2002), Wang \& Fan (2009) and Wang (2005) systematically analyze the differences and similarities between conceptual blending theory and conceptual metaphor theory, pointing out their respective advantages in the explanation of certain linguistic phenomenon. In the field of translation, Dong \& Feng (2005) discuss the cognitive explanation in the text translation from the perspective of the conceptual blending of format and meaning and that of culture and images. Hu (2004) and Qi (2010) believe that the 
process of translation is in accordance with the establishment of integration networks structure. In the aspect of the combination of conceptual blending theory and creative language formation, Luo (2010) discusses the parody in the advertisement with the help of conceptual blending theory. Liu (2006) and Liu (2006) explore humor based on conceptual blending theory. Shen \& Liu (2006) and Bai \& Chen (2010) have touched upon the analysis of internet language with the help of this theory. Concerning literature, Wang (2008) explore the metaphors in the Bible, while Wang \& Sun (2008) takes "Of studies" as an example. Other works like "The Thought Fox" has been analyzed from the perspective of conceptual blending, image schema and conceptual metaphor (Huang, 2009).

It is not difficult to notice that the focus of the researches of conceptual blending theory in China lies in the exploration of application of this theory. As for the researches of the application of conceptual blending theory in the explanation of internet language, the quantity and covering are limited. As a result, there is still large space in the research in this field.

\section{RESEARCH DESIGN}

\section{A. Feasibility of the Internet Catchwords Research}

First, internet catchwords need to be analyzed. One of the reasons that internet catchwords can win people's heart is that they are not the literal combination of words or phrases but the reborn of the old common phrases or utterances based on our background information and imagination. Considering this feature, it is worthwhile for us to find out the implication of these internet catchwords.

Second, internet catchwords can be analyzed. Internet catchwords demand a creative theory to analyze them. Meanwhile, an important function of conceptual blending theory is the provision of global insight. In other words, a blend is an imaginative feat that allows us to "grasp" an idea by viewing it in a new way (Evans \& Green, 2006). According to Fauconnier and Turner, conceptual blending achieves this by reducing complexity to human scale: the scope of human experience. The reason why two seemed irrelevant objects can be connected is that people produce association of similarity. As a result, people make use of the combination of the two objects to explain, comment and express their real feelings towards the world. Even though the physical property of the objects plays an important role in cognition, the way people understand objects is not only by visual sense but the combination of several senses. This combination enables people to find the similarities between different objects according to their experience (Zhao, 2001). To guarantee the successful mapping in the blending network, we extend the descriptive apparatus by introducing the notion of mapping scope. The mapping scope is best understood as a set of constraints regulating the correspondences which are eligible for mapping from a concept onto another one. Essentially, the mapping scopes reflect our conceptual experiences in dealing with the world around us (Ungerer \& Schimid, 2001). As a result, when hearing "Jim is a pig", we can infer that "Jim is stupid" because we share the background knowledge that in China, pig has the image of slow and silliness. That is also the reason why the net citizens can understand the internet catchwords even if it is the first time that the net citizens read them, for the net citizens all share the similar mapping scope. When we produce or listen to a piece of discourse, we unconsciously fill in an incredible amount of information. If not, we would certainly not be able to understand even the simplest piece of discourse. Since the net citizens all have some internet-surfing experience and common background knowledge, they share a large mapping scope in internet. This common background knowledge can be activated during conceptual blending so as to guarantee the possibility of conceptual blending. For example, when hearing "Da Jiang You (buying soy sauce)", people will associate it with a hit interview: When questioned the opinion of the "sex picture scandal", one citizen said: "I don't care. I just go outside to buy soy source". After the interview, "Da Jiang You (buying soy sauce)" has become a hit internet catchword. As a result, people can easily work out the implication of the phrase "people do not care about something".

The crucial insight of blending theory is that meaning construction typically involves integration of structure that gives rise to more than the sum of its parts (Evans \& Green, 2006). As a result, through conceptual blending, people can always deprive something new from the original words or phrases. This is a dynamic and creative process.

\section{B. The Significance of the Research}

Internet catchwords have become another mirror of social culture and human psychology. Analyzing internet catchwords can help people grasp the trend of the people's taste and the desire hoping to be identified.

Furthermore, conceptual blending theory is a relatively new approach. In the past, people often take it for granted that internet catchwords are only entertainment but not a linguistic phenomenon to study. The difficulty to study a changing language phenomenon also stops people. Considering this, to use conceptual blending theory to study internet catchwords will be a safe and good choice. In addition, compared with the application of conceptual blending theory in literature, linguistic acquisition, metaphor, the adoption of this theory in internet catchwords studying will be a refreshing one.

\section{The Choices of Research}

Of all the current internet catchwords in 2010, according to their frequency of citation in the news and conversation, this paper chooses three typical internet catchphrases and three utterances to analyze. They will help the readers understand the cognitive mechanism of meaning construction of internet catchwords. 


\section{Research Analysis}

Adopting the analysis approach of Ungerer and Schimid (2001), the author will neglect the fourth, namely so-called "generic space" proposed by Fauconnier and Turner in the following analysis, because it does not add anything that we regard as essential for understanding the network model (Ungerer \& Schimid, 2001). The following are the typical examples of catchphrases and utterances.

1) Phrases:

a) "Pi Li (Thunderbolt)"

This phrase prompts for an integration network in which there are two inputs. In input 1 , it contains an INFORMATION frame, containing many kinds of media such as newspaper, television, radio and etc, which are used to inform people of current affairs meanwhile affect people's mood or feeling. In input 2, it contains a NATURE frame, including thunder and lightning which would scare or hurt people. What distinguishes this type of network is that only one frame (here, the NATURE frame rather than INFORMATION frame) serves to organize the blend. In other words, the framing input, NATURE frame, provides the frame, including the roles for lightning or thunder and the consequence to be shocked and hurt, while the focus input that is the INFORMATION frame provides the relevant elements: the information. As for this example, INFORMATION takes the roles of thunder and lightning to affect people's emotion. In this blend, thunder or lightning endows the shocking or ridiculous information with concrete images. As a result, on the internet, when a net citizen says "Pi Li (Thunderbolt)", people can infer that he or she has really been shocked by certain news or event. The details are shown in the following figure 4.1.

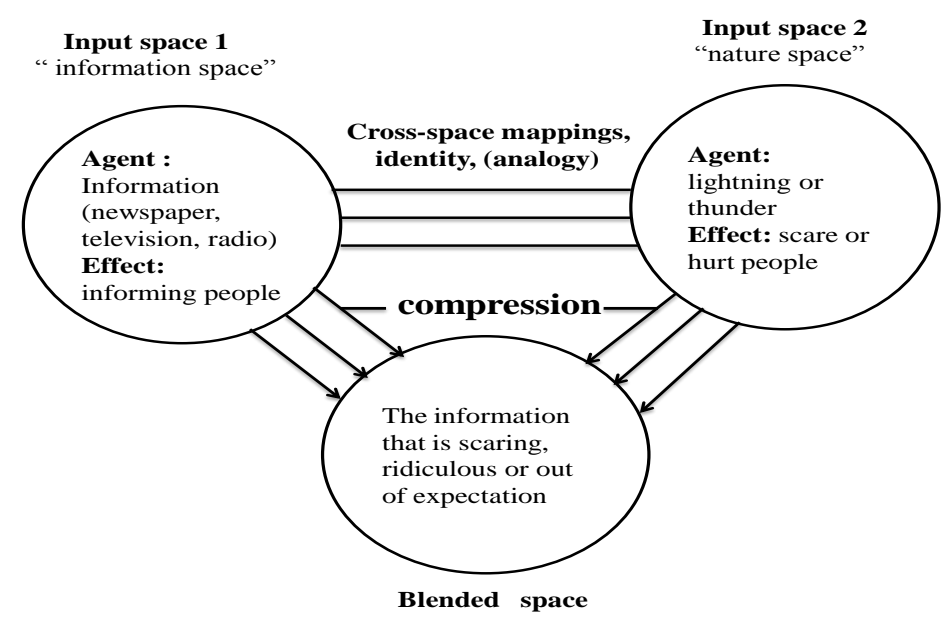

Figure 4.1 conceptual blending network of "Pi Li (Thunderbolt)"

b) "Pi Tui (split)"

This utterance implies two inputs which have different organizing frames: the frame of PLAYBOY who loves at least two women simultaneously and easy to fail in all relationships; the other one is the SPLIT frame in which people separate their legs to different directions and easy to lose balance. The frame in the blend draws from the frame of PLAYBOY---divides his love into several parts and gives them to different women---as well as the frame of SPLIT---the action that divides his legs to different directions. Part of the imaginative achievement here is finding the two frames that, however different, both can contribute to the blended activity in ways that are compatible (Evans \& Green, 2006). The playboy in input 1 can be compatible with the "people splitting". The direction of "dividing love" in input 1 can be compatible with the direction of "splitting legs" in input 2 . However, there are also some differences between them. The connotations behind "dividing love" and "splitting legs" are different, so is "falling in love" with "losing balance". In input 1 "dividing love" is an irresponsible action. Meanwhile, "splitting legs" is more like an exercise. In emotion aspect, "Failing in love" is more serious than "losing balance". In a word, the compatible elements between "playboy" and "people splitting" and those between the two actions are the foundations of this blending, implying the possibility to compare these two actions. Meanwhile, the contrast between them leads to the new and ironic meaning of "splitting legs". In this blend, Splitting becomes a concrete image of the inconstant people. It forms a metaphor that compares the action of inconstant people to the movement of splitting legs.

The details are in the figure 4.2 . 


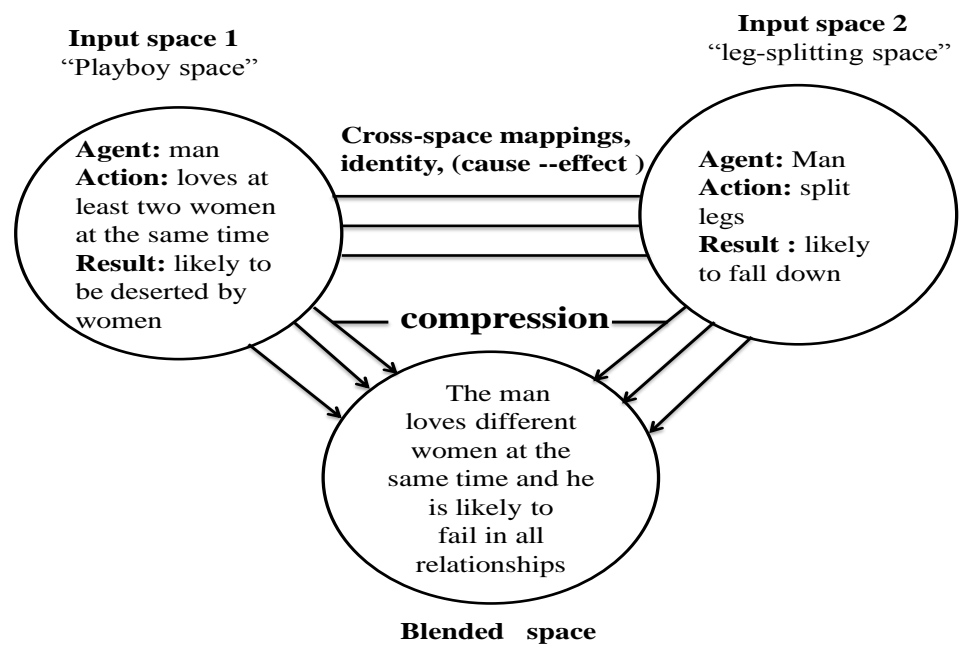

Figure 4.2 conceptual blending network of "Pi Tui (Split)"

c) "Lu Guo (pass-by)"

This phrase sets up an integration network in which there are two input spaces: one is the NET CITIZEN frame which shows a net phenomenon that some net citizens only causally browse some internet information without giving their own opinions; the other one is the PASSER-BY frame which shows the scene that people only pass some place without lingering. The two inputs contain the similar structure. As a result, the similar behavior pattern of these two kinds of people becomes the link of the two inputs. Elements of the similar behavior pattern are mapped onto counterparts in each of the input spaces, which motivate the identification of cross-space counterparts in the input spaces (Evans \& Green, 2006). However, we only elect part of the information from the inputs. In other words, not all the structure from the inputs is projected to the blend, but only the relevant information, which is required for purposes of local understanding. In this example, we only focus on the behavior pattern but not the companion or vehicle of the passer-by or net citizen. Together with the elements in the two inputs spaces, we can complete this blend with our background knowledge of these two kinds of people. Then the emergent structure appears which contains some information from the two inputs and also something new. Since the net citizens have the experience of only going through some information without responses. They would easily find the similarity between these two actions. As a result, it is not difficult for the Net citizens to draw the conclusion that the concrete "Lu Guo (pass-by)" in our daily life can be used to modify the abstract action in the virtual world.

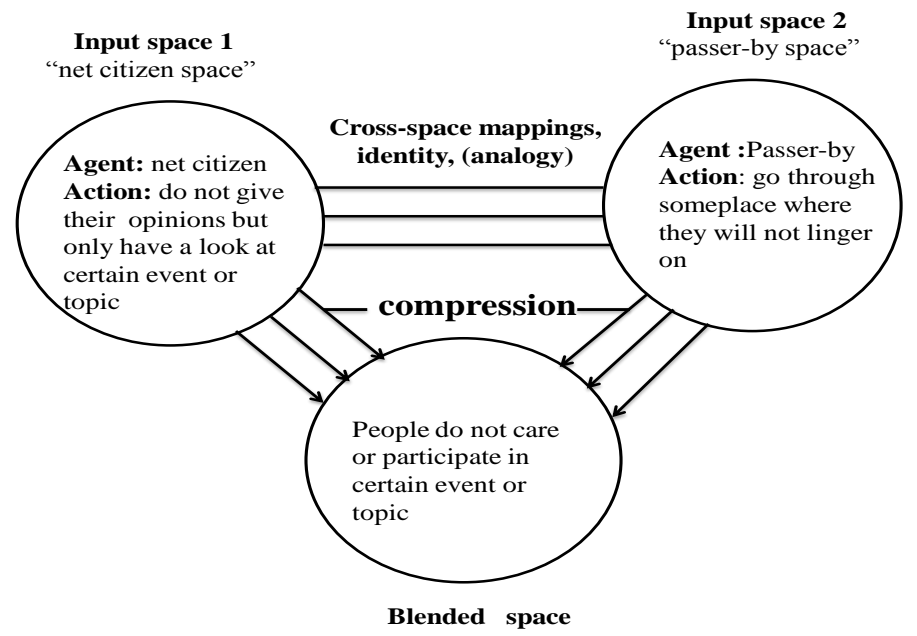

Figure 4.3 conceptual blending network of "Pi Tui (Split)"

2) Utterances:

a) "Li Xiang Hen Feng Man, Xian Shi Hen Gu Gan (the dream is fantastic but the reality is cruelty.)"

This utterance prompts for an integration network in which one input contains a DREAM AND REALITY frame. The dreams people hold can be either very great or small and can be either few or many. The reality can be either very favorable or miserable. The second input contains the FIGURE frame which shows two opposite figures: plump and 
slim. In these two inputs, there are four important images: dream, reality, plump figure and slim figure. These four seemed-irrelevant images are linked by cross-space mappings of identity, which undergo compression. In other words, the two images of the first input space amalgamate with the construction activated in the second space and the topology of the first space is overruled by the principle of integration. The result of that is the establishment of an emergent structure in the blended space combining these four images. The meaning contained is more than the sum of its component parts. During the blending, the background information about these four images is completed into the blend. Different figures will give people different impression and psychology feeling. The reader can use the different impression of these two figures to deduct the condition of the dreams and reality. The greatness of the dreams is represented by the visual feeling of the plump figure which is mellow and full, while the cruelty of the reality is showed by the visual feeling of the slim figure that is skinny and delicate. In this way, the once-irrelevant things can be connected. Moreover, this novel metaphor adopts a very relaxing tone to create humor effect and show a concrete image of the abstract conception of greatness and cruelty. Seeing this metaphor, people can easily get the information that the competitive reality will make it hard for people to accomplish their dreams even though the dreams are wonderful. Hearing this, people may show a bitter smile about the gap between ideality and reality.

The details are shown in the following figure 4.4:

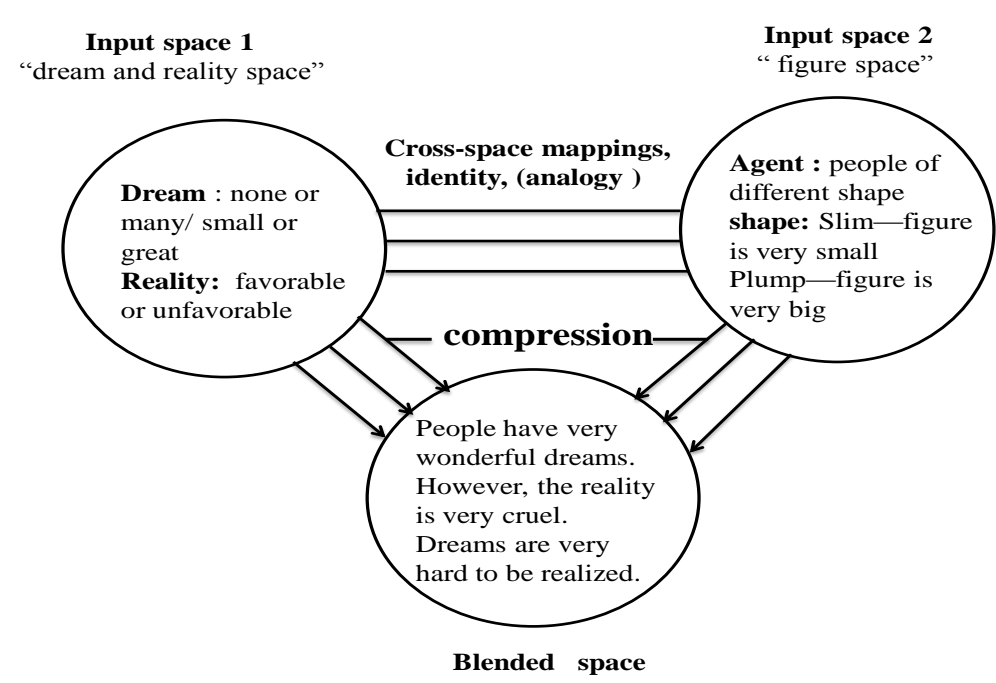

Figure 4.4 conceptual blending network of "Li Xiang Hen Feng Man, Xian Shi Hen Gu Gan (the dream is fantastic but the reality is cruelty.)"

b) “La Zhe Lao Po De Shou Jiu Xiang Zuo Shou La You Shou (when holding wives' hands, people feel like holding their own hands.)"

The utterance sets up an integration network in which there are two input spaces: one relates to the situation that a husband hands his wife's hand and the other relates to a person hands his or her own hand. Each of the spaces in this example contains the frame hand hands another hand, which is the same to the blend that has the additional schema relating to a handing frame. The similar structure of these two frames contains schematic information relating to handing, which motivates matching operations and thus cross-space connections between the two inputs. In the blend, we have two kinds of "hand in hand": one is husband hands his wife, the other one is a person's "own right hand hands left hand". Moreover, in the blend the two "hand in hand" are being compared, in which the husband hands his wife is treated equally as people hands their own hand. However, wife's hand is definitely not the husband's own hand, which shows that the husband has no passion and feeling towards his wife. Despite this, we achieve valuable inferences as a result of setting up the conceptual blend. Indeed, it is only by virtue of blending that we can compare the two kinds of hand in hand.

In achieving this blend, the first process to occur is to select relevant information from the inputs to blend. Not all the information in the input spaces is projected. For example, information is not projected relating to how the hand looks like, how long the handing lasts, or where the handing occurs. Instead, information is projected that is sufficient to accomplish the inference. As in this blend, we only project the feeling when "hand in hand". Secondly, the structure that is selectively projected into the blend is composed and completed. According to our experience, we can easily figure out the different underlying feeling of different "hand in hand". In this blend, we compare the different feelings between husband hands wife's hands and people hand their own hands. Upon running this blend, a new meaning has emerged as a result of composition and completion.

The conceptual blending is illustrated in the following figure 4.5: 


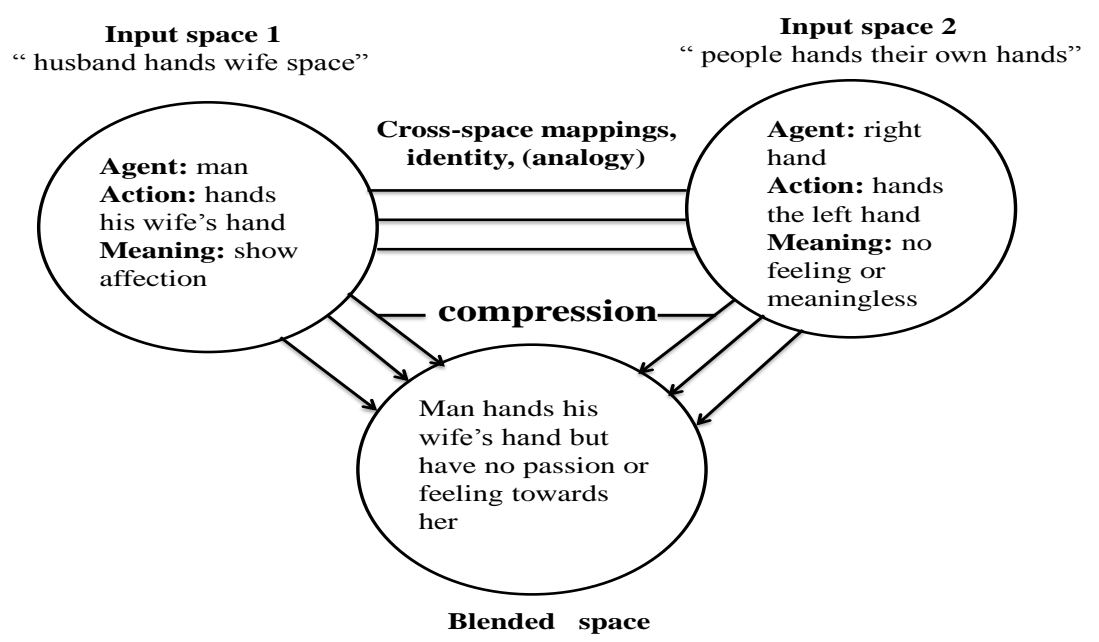

Figure 4.5 conceptual blending network of "La Zhe Lao Po De Shou Jiu Xiang Zuo Shou La You Shou (when holding wives' hands, people feel like holding their own hands.)"

c) "Ren Shen Jiu Xiang Ge Cha Ji Chong Man Le Bei Ju He Xi Ju (life is like the tea table which holds cups and dishes.)"

This utterance prompts for an integration network in which contains two input spaces. In the LIFE input, there is an abstract life and all the elements that a life contains such as happiness or sorrow. In the TEA TABLE input, there is a tea table, cups and dishes. At the first glimpse, it seems that there is no connection between life and tea table. But after reading it again, we will find that "Bei Ju (cups)" is the homophonic tone of "Bei Ju (tragedy)" in Chinese. Moreover, "Xi Ju (dishes)" is the homophonic tone of "Xi Ju (comedy)" in Chinese. In this way, the metaphor is established. In LIFE space, "life is full of tragedy and comedies". Meanwhile, the common structure which is "container-loaded goods" in the two inputs becomes the link between these two inputs. Through selective projections and conceptual blending, the emergent structure of this blending network is formed by these elements. In this blend, while the TEA TABLE input becomes the focus frame, LIFE input turns to be the framing input to organize the blend. The real meaning of this utterance appeared: life is full of tragedies and comedies (as the following figure 4.6 shows).

We can find that this utterance makes use of the homophonic relationship between "Bei Ju (cups)", "Xi Ju (dishes)", "Bei Ju (tragedy)", and "Xi Ju (comedy), which not only illustrates the real meaning of life but also makes it vivid, humorous and easy to remember. As a result, homophonic relationship has often been adopted to create new expression to establish two contexts---the original meaning and implying meaning---to work out the real meaning of the utterance.

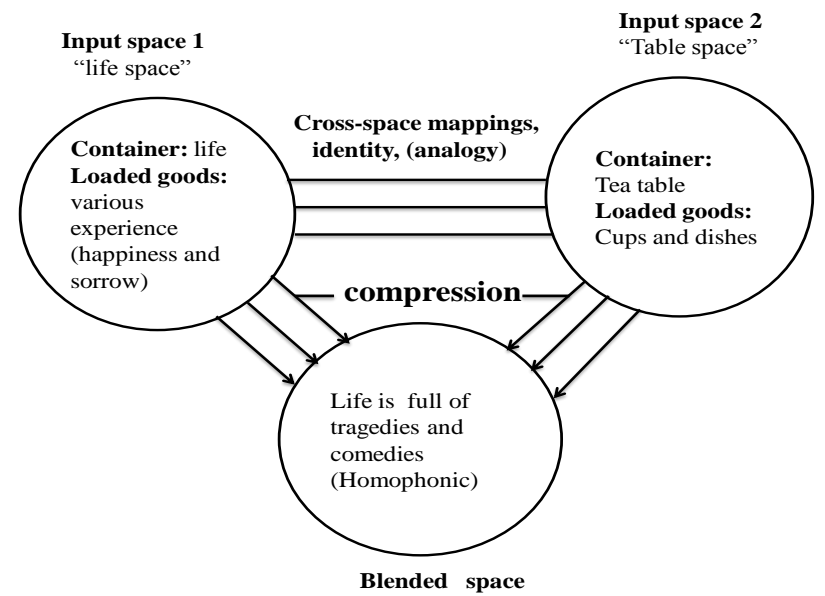

Figure 4.6 conceptual blending network of "Ren Shen Jiu Xiang Ge Cha Ji Chong Man Le Bei Ju He Xi Ju (life is like the tea table which holds cups and dishes.)"

\section{CONCLUSION}

Language is dynamic but not a stable system of man-made symbols. Internet catchwords are also the productions of this developing and open-minded world. Internet catchwords have become the flavoring agent of people's life, even the 
ice-breaker of strangers.

Blending theory is well suited to capture the conceptual indeterminacy of internet catchwords and open-endedness of the online cognitive processing. During this process, the relevant knowledge based on our experience will be activated and influence our ability to produce and understand the language related to it.

Blending theory emphasizes the dynamic and mutable aspects of blending and its role in meaning construction. By applying the conceptual blending theory into the analysis of internet catchwords, we can see the daily linguistic phenomenon in a new and dynamic perspective and develop a deeper understanding of the cognitive mechanism behind them. This is a process from the macro-research to micro-research which is often neglected by people.

\section{REFERENCES}

[1] Aihua Hu. (2004). A Study on Conceptual Integration Theory and the Cognitive Process in Translation. M.A. Degree dissertation, Hunan University. http://epub.cnki.net/grid2008/detail.aspx?QueryID=3\&CurRec=1 (accessed 29/6/2010).

[2] Dunping Liu. (2007). The explanatory power of conceptual integration for verbal humor, Journal of Sichun International Studies University, 7, 80-88.

[3] Evans, Vyvyan \& Melanie Green. (2006). Cognitive Linguistics—an Introduction. Edinburgh: Edinburgh University Press, 367-444.

[4] Fauconnier, Gilles. (1997). Mappings in Thought and Language. Cambridge: Cambridge University Press.

[5] Fauconnier, Gilles and Mark Turner. (1998a). Conceptual integration networks, Cognitive Science, 22, 2, $33-187$.

[6] Fauconnier, Gilles and MarkTurner. (1998b). Principles of conceptual integration, in J.-P.Koenig (ed.), Discourse and Cognition. Stanford, CA: CSLI Publications, 269-83.

[7] Fauconnier, Gilles. (1999). Methods and generalizations, in T. Janssen and G. Redeker (eds.), Cognitive Linguistics: Foundations, Scope and Methodology. Berlin: Mouton de Gruyter, 95-128.

[8] Fauconnier, Gilles and Mark Turner. (2000). Compression and global insight, Cognitive Linguistics, 11, 3-4, $283-304$.

[9] Fauconnier, Gilles and Mark Turner. (2002). The Way We Think: Conceptual Blending and the Mind's Hidden Complexities. New York: Basic Books.

[10] Grady, Joseph, Todd Oakley and Seana Coulson. (1999). Blending and metaphor, in R.W. Gibbs and G. Steen (eds.), Metaphor in Cognitive Linguistics. Amsterdam: John Benjamin, 101-124.

[11] Grady, Joseph. (2005). Primary metaphors as inputs to conceptual integration, Journal of Pragmatics, 37, $1595-614$.

[12] Guirong Dong \& Qi Feng. (2005). Cognitive mechanism of translation from the perspective of Faucnnier's conceptual integration, Shanghai Journal of Translations, 1, 33-36.

[13] Guohui Liu. (2006). A cognitive approach to the generating mechanism of verbal humor from the 3D of SCF, CI and CB, Journal of Sichun International Studies University, 3, 135-139.

[14] Hua Huang. (2009). Language: the most important approach to understanding man---an analysis of The Thought Fox from cognitive perspective, Foreign Language Research., 6, 1-4.

[15] Hua Huang. (2002). A comparative study of conceptual metaphor theory and conceptual integration, Journal of Sichun International Studies University, 1, 93-96.

[16] Hui Zhang \& Bo Yang. (2008). Mental spaces and conceptual blending: theoretical developments and their applications, Journal of PLA University of Foreign Languages. 1, 7-14.

[17] Jiehong Bai \& Minzhe Chen. (2010). A study of on-line meaning construction of Chinese net-words--with"X Ke" as an example. Foreign Language Research, 2, 25-30.

[18] Jinxin Qi. (2010). The Cognitive Process of Translation Tang Poems from the Perspective of Conceptual Integration Theory. M.A. Degree dissertation, Southwest University. http://epub.cnki.net/grid2008/detail.aspx?QueryID=74\&CurRec=1 (accessed $13 / 1 / 2011)$

[19] Jiankun Wang \& Qiyao Sun. (2008). The role conceptual integration plays in text coherence, Foreign Language Research, 1, 104-107.

[20] Lei Wang. (2008). The conceptual blending theory applies to Biblical parables, Foreign Language Research, 4, 76-79.

[21] Meiyan Lu. (2010). A comparative study on concept integration theory and relevance theory, Journal of Sichun College of Education, 11, 79-82.

[22] Ningling Wei. (2010). The Humanistic Default and Complement of CBT: A case study of the client's story reconstruction in narrative psychotherapy. M.A. Degree dissertation, Southwest University. http://epub.cnki.net/grid2008/detail.aspx?QueryID=144\&CurRec=1 (accessed 13/1/2011).

[23] Qinling Wang. (2005). The comparative study of conceptual metaphor theory and conceptual blending theory, Foreign Language Research, 1, 42-46.

[24] Qiqiang Zhou \& Jiehogn Bai. (2006). The cognitive mechanism of English blending words, Foreign Language Teaching and Research, 3, 178-183.

[25] Shengjie Luo. (2010). The cognitive study on parody in advertisements, Foreign Language Research, 1, 52-56.

[26] Shaohua Wang \& Xin Fan. (2009). Analysis of text coherence from the perspective of Conceptual metaphor and conceptual blending theory, Foreign Language Research, 4, 24-29.

[27] Tong Shen \& Jun Liu. (2006). The conceptual analysis of the internet language from CIN, Shandong Foreign Language Teaching Journal, 5, 54-59.

[28] Turner, Mark and Gilles Fauconnier. (1995). Conceptual integration and formal expression, Metaphor and Symbolic Activity, 10, 183-203.

[29] Turner, Mark and Gilles Fauconnier. (2000). Metaphor, metonymy and binding, in A. Barcelona (ed.), Metaphor and Metonymy at the Crossroads. Berlin: Mouton de Gruyter, 264-86.

[30] Ungerer, F. \& H. J. Schimid. (2001). An Introduction to Cognitive Linguistics. Beijing: FLTR. 
[31] Xia Meng. (2004). Evaluation of conceptual blending theory, Journal of Xi'an International Studies University, 12, 4-6.

[32] Yanfang Zhao. (2001). An Introduction to Cognitive Linguistics. Shanghai: Shanghai Foreign Language Education Press.

[33] Zhonghui Huo. (2010). The Complement Research of Prototype Theory and Conceptual Blending Theory on Euphemism. M.A. Degree dissertation, Hei Longjiang University. http://epub.cnki.net/grid2008/detail.aspx?QueryID=214\&CurRec=1 (accessed 13/1/2011).

[34] Zhengyuan Wang. (2006). Development of conceptual blending and its frontier issues, Journal of Sichun International Studies University, 11, 65-70.

[35] Zhengyuan Wang. (2007). Analysis on the blending mechanism of meaning production of word phrase, Journal of Sichun International Studies University, 5, 65-70.

Meng Li was born in Hunan, China in 1988. She received her B. A. Degree in English from Beijing Forestry University, China in 2006.

She is currently a graduate student in the School of Foreign Language, Beijing Forestry University, Beijing, China. Her research interests include cognitive linguistics and second language acquisition.

Yueqin Gao was born in Beijing, China in 1969. She received her M.A. degree in linguistics from Beijing University of Aeronautics and Astronautics, China in 2001.

She is currently an associate professor in the School of Foreign Languages, Beijing Forestry University, Beijing, China. Her research interests include sociolinguistic, pragmatics and cognitive linguistics. 